\title{
Reducing Retroactive Interference through the Use of Different Encoding Techniques: An Exploration of Pre-Test/Post-Test Analyses
}

\author{
John M. Cumming, Ph.D. (Corresponding author) \\ School of Education, Colorado State University \\ Fort Collins, CO 80523, USA \\ Tel: 1-970-491-6317_E-mail: John.Cumming@colostate.edu \\ Michael A. De Miranda, Ph.D. \\ School of Education and \\ Department of Electrical and Computer Engineering \\ Colorado State University, Fort Collins, CO 80523, USA \\ Tel: 1-970-491-5805 E-mail: mdemira@engr.colostate.edu
}

Received: April 9, 2012

doi:10.5430/ijhe.v1n1p22
Accepted: May 2, 2012

URL: http://dx.doi.org/10.5430/ijhe.v1n1p22
Published: May 15, 2012

\begin{abstract}
Retroactive interference (RI) in list learning occurs when the learning of a second list of words interferes with the recall of the first learned list. Having the lists be thematically different can reduce retroactive interference within list learning; however, this study demonstrates how RI can be reduced when the lists contain similar words. Words can be organized by way of encoding (verbally and visually). Interference occurs when two lists are encoded the same way; therefore, encoding two lists in different ways reduces RI. Ninety-three participants were randomly assigned to 1 of 6 conditions. Participants who encoded one list visually and one list verbally retained more words on final recall from list one, than participants who encoded both list the same way. Two control conditions were used to assess highest recall. The results demonstrated that RI can be reduced when two lists are encoded in different ways. A second experiment using modified methods was also conducted with similar results.
\end{abstract}

Keywords: Retroactive interference, Encoding, List learning, Value added models

\section{Introduction}

Forgetting learned information or past experiences, like what you had for dinner last week, is a common experience for most people. Within the fields of psychology and education memory and forgetting have been well researched. The common overarching theme that aligns with common sense is that humans posses an innate ability to cognitively retain information, but at the same time we can forget information. An argument/question from a cognition perspective is do humans completely lose the information or is it obtainable but we just have problems retrieving it and are there ways to make information retrieval easier? From an educational perspective a significant questions educators wrestle with is how to present material to students' that best facilitates their learning?

\subsection{Research on Memory and Forgetting}

Hermann Ebbinghaus' classic research in the 1880's, as cited by Burns and Gold (1999), explained a concept know as the forgetting curve. As time increases after learning a list of words or concepts a persons memory of recall of these items decrease. While time from learning to retention was a key factor of forgetting in Ebbinghaus' experiments, other unexplained variables effecting retention could not be excluded.

Multiple studies by Chandler (1989, 1993), Bower and Mann (1992), Bower, Thompson-Schill and Tulving (1994), and Bower, Wagner, Newman, Randle, and Hodges (1996) demonstrated the notion of retroactive interference (RI). Retroactive interference can be explained as the learning of new information that interferes with the recall of previously learned information. Bower et al. (1994) demonstrated that RI can be increased when the new information is similar to the previously learned information. Studying RI typically involvesusing two lists of words. For example, list A is read 
by the researcher and when all items have been read aloud the participants are asked to recall as many words as they can. The researcher then reads list B and at the end of the list the participants are asked to recall as many words as they can. After this has been completed the researcher instructs the participants to write down as many items that they can remember from list $\mathrm{A}$. The number recalled from List A after the second time around is much smaller when the group has also been asked to learn list B. When the experimental condition is the reading and recall of list A sans list B, the recall rate of list A is much higher (Marsh, Landau, \& Hicks, 1996). The reason underlying RI has long been debated within the literature. According to Chandler $(1989,1993)$ the memory trace from list A has been altered by incoming information, therefore RI occurs because of a loss of retention. On the other hand Bower et al. (1994) argued that RI is simply an overload during recall, not a loss of retention. If Bower and his colleagues $(1992,1994)$ are correct then an assumption that reducing the overload during recall can decrease RI can be made.

Ongoing research has involved reducing RI by informing the participants that list B's words are different in some way than list A's words. Bower and Mann (1992) were able to reduced RI when list B was composed of a non-obvious feature that did not accompany list A. When the participants knew this distinction they were able to recall about the same number of words from list A during the final recall trial. This finding sparked further research investigating other kinds of post information cues that would also reduce RI (Marsh et al., 1996). Marsh and his colleagues informed participants that the second list of words were part of a song or part of a children's nursery rhyme. This strategy was found to reduced RI. These studies reduce RI by cuing participants of differences between the two lists.

\subsection{Memory and Student Learning Within Educational Settings}

Retroactive interference is often studied through list learning exercises but has also been examined in educational settings (Fraser, Ma, Teteris, Lee, Wright, \& McLaughlin, 2012). Fraser and her colleagues specifically demonstrated RI with medical students training on different cardiac murmurs. Oftentimes educational researchers discuss retrieval and forgetting in terms of working memory capacity (Graf, Lin, \& Kinshuk, 2008; Alloway, 2006; Rassaian, 2001), student learning style (Kazu, 2009; Kamuche, 2005), and differentiated teaching style (Brock \&Joglekar, 2011; Coller \& Shernoff, 2009; Michel, Cater, \& Varela, 2009).

\subsection{Working Memory as Capacity}

Working memory is the storing and manipulation of new information (Baddeley \& Hitch (1974). Research has demonstrated that in order to not forget this new information in working memory it needs to be transferred to long term memory. This transfer can be done through the use of exploratory thinking and metacognitive strategies like self quizzing (Karpicke, Butler, \&Roediger, 2009 and Rassaian, 2001).

Educational researchers have investigated forgetting or non-learning as a problem with working memory capacity. For example, students with low working memory capacity may struggle to learn foundational knowledge that intern inhibits their learning of more complex material (Alloway, 2006). Additionally, Graf, Lin, and Kinshuk (2008) have argued that students with low working memory capacity are not necessarily low achievers; they just have a different learning style which tends to be more towards active and visual learning.

\subsection{Student Learning Style}

Student learning style appears to be moderated by working memory capacity but other variables may also affect learning style. Kazu (2009) explained that students learn differently due to many different cognitive learning processes, therefore Kazu asserts that all students should be accurately assessed in order to provide an adequate mode of teaching. Kamuche (2005) described that learning style is important but teaching style is equally important. For example, students performed better on a statistics test when their learning style was matched to a similar teaching style compared to unmatched students and teachers (Kamuche, 2005). Assessing learning style and matching to a comparable teaching style may facilitate learning, but in large-scale educational environments like public school classrooms it becomes increasingly difficult to achieve. The alternative to spending valuable time and resources assessing every student is to deliver teaching using diverse methods that may span across a larger gradient of student learning styles.

\subsection{Differentiated Teaching Styles}

Recent efforts to address a wide range of student learning styles have focus on the notion of differentiated instruction. This approach to teaching advocates active planning for and attention to student differences in classrooms, in the context of high quality curriculums. Michel, Cater, \& Varela (2009) found that teaching courses solely through activities and exercises produced learning outcomes (test scores) that were not significantly different than scores from students who where in lecture only courses. Therefore, differentiated instruction can be characterized as a deliberate act of modifying instruction or an assignment in order to customize the effect to match the particular developmental level and skills of a student or group of students. The ideal is to provide equivalent learning activities that cater to the students' strengths but 
bring all of the students to the same learning objective. On one end of the spectrum is the one-size-fits-all learning activity; while on the other end is the completely individualized learning plan for each student. Differentiating the teaching instruction within a course can have profound effects on learning outcomes and student engagement (Coller \& Shernoff, 2009).Even when teaching only through lecture, adding visual elements (pictures, videos, tables, and other graphics) effectively compliments instructional practice (Brock \& Joglekar, 2011). Learning through different methods holds the potential to impact retention.

\section{Purpose and Hypotheses}

Is cuing the participants always necessary for reducing RI? Within the introduction section of this manuscript, the idea that information can be learned in different ways became apparent. Specifically related to RI, it is logical that encoding list A verbally by repeating it to yourself and then encoding list B visually; for instance picturing the word in your mind will reduce RI when recalling list A during the final recall trial. The same effect is also plausible when list A is visually encoded and list B is verbally encoded. More words will be retained from list A when the two lists are encoded in different ways rather than when encoding both lists verbally or both lists visually. The two lists can have similar types of words but after encoding they will be categorized differently. Encoding two similar lists, each in different ways will lead to less RI compared to encoding the two lists the same way.

It is hypothesized in this investigation that encoding two lists in different ways reduces retroactive interference. A possible confound to experiment one was that the 'visual' information was presented by the researcher reading the words and having the participants picture the word in a way that stands out to them. This does mix visual with verbal because the researcher said the words aloud. Experiment two attempted to alleviate the possible confound from study one by having the researcher present the 'visual' words by showing pictures of the words to the participants rather than announcing the words.

\section{Methods}

\subsection{Experiment One}

\section{1) Participants}

The participants included 93 Introductory to Psychology students who received credit for their participation. The participants were randomly organized in groups ranging from one to six, evenly spread out in the room, so they could not communicate with each other. The variability in group size was due to participant no shows. The mean age of the participants was 22 and $53 \%$ of the sample identified as being male.

\section{2) Procedure}

The small groups of participants were randomly assigned to one of six conditions. A brief demographics form and a manila envelope were distributed to each participant.The participants were instructed to put the demographic form in the envelope when they were done, but were instructed to leave it open because more paperwork was going to be added to it later. Each participant received a piece of lined paper that was labeled with the number one at the bottom right of the page. This procedure along with the word lists stayed constant for each condition. Appendix A contains list A (the list of interest) and list B (the interference list). The lists consisted of 16 words that were spoken at an even pace by the researcher. An even pace was four seconds between each word and the entire list took a little over a minute to read. The word lists were the same for each condition. Each of the six conditions heard list A. In addition to list A, four of the six conditions also heard list B. The other two conditions had a puzzle to work on for five minutes rather than listening to list B.

For the first condition (list $\mathrm{A}=$ verbal / list $\mathrm{B}=$ verbal)the researcher instructed the participants to try to remember list $\mathrm{A}$ by repeating the words as many times as they could to themselves before the next word was given. Consider this verbal encoding. After all of the words were given the participants had three minutes to write down as many words as they could remember. After the three minutes the researcher instructed the participants to put their answer sheet into the manila folder. The researcher then passed out another lined answer sheet that had the number two printed on the bottom right. The participants were instructed to rehearse the words from the upcoming list in the same manner as they did with the first list. After all of the words had been given they were allowed three minutes to recall as many words as possible. After the three minutes the researcher instructed the participants to put their answer sheet into the manila folder just like they had done before. The researcher then passed out another answer sheet with the number three printed on the bottom. The participants were instructed to recall as many words as they could from the first list. After three minutes, the participants were instructed to put their answer sheet in the folder. The participants were then debriefed and were free to leave. 
The second condition (visual/visual) was exactly the same as the first, however, instead of instructing the participants to repeat the word as many times as they could to themselves they were instructed to visualize the word in a way that stands out to them. Consider this visual encoding. For example, if the word is purple the researcher told them to imagine themselves being painted purple. This was done for both lists. The first condition encoded two different lists verbally whereas the second condition encoded two different lists visually.

The next two conditions (condition $3=\mathrm{verbal} / \mathrm{visual}$; condition $4=$ visual/verbal) were conducted in the same manner as the first two but this time the participants alternated their encoding method from one list to the next. To explain this further, the third condition involved verbal encoding of list A and visual encoding of list B. The distribution of numbered answer sheets and the amount of recall time stayed constant between each group and condition. The fourth condition involved visual encoding of list $\mathrm{A}$ and verbal encoding of list $\mathrm{B}$.

The final two conditions had no interference list (condition $5=$ verbal/filler; condition $6=$ visual/filler). These conditions are considered controls in order to investigate retention with nothing interfering with their memory. The fifth condition involved verbal encoding of list A. After the participants recalled words from list A, they were given a filler activity to work on for five minutes. The filler activity was Tangram shapes that when aligned in the correct pattern make a square. After the five minutes passed, the researcher passed out an answer sheet with the number three printed on the bottom right. Note that answer sheet number two was not used in the fifth and sixth conditions because there was no list B. The participants were given two minutes to once again recall as many words as they could from the list that they heard (list A) before they played with the Tangram shapes. The sixth condition was the same as the fifth, but the participants were instructed to encode list A visually instead of verbally. Appendix B displays the condition chart for both experiments.

\section{3) Results}

The initial analysis involved treating the retention percentages of list A (number correctly recalled on answer sheet three divided by the number correctly recalled on answer sheet one multiplied by 100) as the dependent variable and the treatment condition as the independent variable. Table 1 displays the means and standard deviations for retention in terms of condition. The overall retention difference between the lowest retentions rate (condition $1=\mathrm{verbal} / \mathrm{verbal}$ ) and highest retention rate (condition $6=$ visual/filler) was 35 percent.

A one-way Analysis of Variance, was used to assess retention in terms of condition, $F(5)=10.43, p<.001$. The post hoc (Tukey) indicated that the statistically significant differences occurred between the visual/filler condition and the visual/visual condition, $p=.001$. The visual/filler condition retained more words from list $\mathrm{A}$ than the visual/visual condition while the visual/filler condition did retain more than the visual/verbal condition, it was not found to be statistically significant. Also, the visual/verbal condition retained $15 \%$ more words than the visual/visual condition, but was not significant at the .05 level, $p=.065$. The verbal conditions were similar to the visual conditions, except that their mean retention percentages were slightly lower. The verbal/filler condition retained $32 \%$ more words than the verbal/verbal condition, which was significant at the .05 alpha level. The participants in the verbal/filler condition retained more words than the participants in the verbal/visual condition but this was found to be not significant, $p=.087$. Participants in the verbal/visual condition retained $15 \%$ more words than participants in the verbal/verbal condition, but also was not statistically significant at the .05 alpha level, $p=.104$. What did stay constant was the close percentages between the verbal/verbal and visual/visual condition (10\% difference), the verbal/visual and the visual/verbal condition $(10 \%)$, and finally between the verbal/filler and visual/filler conditions $(2.5 \%)$. Overall, recall was highest when list A was visually encoded.

The results of the initial ANOVA indicate minimal differences between conditions that encoded list in similar manners (encoding the same for both lists, conditions 1 and 2; encoding each list differently, conditions 3 and 4; no interference list, conditions 5 and 6). Three $t$ tests confirmed that there were non-statistically significant differences between the three previously mentioned encoding series. The six conditions were then combined into three conditions (same encoding for both lists, different encoding for each list and no interference list) to assess the overall research question of, does encoding lists in different ways reduce RI? Table 2 displays the means and standard deviations for retention in terms of the three conditions. A one-way Analysis of Variance indicated that retention rates differ in terms of encoding condition, $F(2)=21.69, p<.001$. The post hoc (Tukey) tests indicated that there were statistically significant differences between all conditions.

(1)The Gain Score Debate

Gain scores can be seen as unreliable because of their lack of power (Knapp \& Schafer, 2009) and because of the variability associated with the pretest scores (Gupta, Srivastava, \& Sharma, 1988). On the other hand, both gain score 
analysis and ANCOVA are appropriate for different research questions, but ANCOVA should only be used with randomized controlled trials (Ftizmaurice, Laird, \& Ware, 2004). ANCOVA is the most powerful option because it accounts for pretest variance (Cook \& Campbell, 1979), yet the assumptions are rarely completely met; therefore, hierarchical regression should be used instead (Morgan, Gliner, \& Harmon, 2006). Gain scores were initially used followed by ANCOVA, and hierarchical regression.

In order to assess the effect of the encoding series on post test retention scores, while controlling for the variance associated from pretest scores, an analysis of covariance was used. The major assumptions were checked and the only violation was with the within group variances. Sample sizes were fairly equal, therefore, the ANCOVA remains robust against this violation. Table 3 presents the means and standard deviations for the three conditions on post test scores before and after controlling for pre test scores. Results indicate that after controlling for the pre test scores (list A first recall) there was a significant difference between the three conditions (same encoding for both lists, different encoding for each list, no interference list), $F(2,89)=23.37, p<.001$, partial eta ${ }^{2}=.34$. Table 4 displays the ANCOVA table that shows even though there was a significant amount of explained variance associated with the pretest score there were still statistically significant different between the two conditions on post test score.

The assumptions for analysis of covariance were met for the most part but because of concerns in the literature hierarchical regression was used to investigate the effect of experimental condition on posttest score when controlling for the pretest score (Morgan et al., 2006). The assumptions of linearity, normally distributed, and uncorrelated errors were checked and met. Table 5 displays that when the pretest was entered alone it significantly predicted posttest score $F(1,91)=171.41, p<.001$, adjusted $R^{2}=.65$. When condition (effects coded) was entered at the second level, it significantly improved the prediction, $R^{2}$ change $=.12, F(3,89)=100.81, p<.001$. The interaction terms (condition by pretest) were entered at the third level, but the $R^{2}$ change $=.003$, was not statistically significant.

Results from the analysis of covariance and the hierarchical regression produced similar results. The ANCOVA is more straightforward than hierarchical regression but does not include possible interaction terns in the model. Both the ANCOVA and hierarchical regression appear to be more appropriate than using the gain score as the dependent variable because with ANCOVA the pretest differences are held constant.

\subsection{Experiment Two}

\section{1) Participants}

The participants for experiment two were 11 volunteers who identified as undergraduate or graduate students. None of the participants in experiment two were part of experiment one. Each participant was randomly assigned to one of two conditions. The participants completed the study individually.

\section{2) Procedure}

Each participant was randomly assigned to one of two conditions (visual/visual, or visual/verbal). These two conditions were similar to conditions two and four from experiment one. The study process and the word lists were the same as outlined in experiment one.

The first condition, visual/visual contained two lists that were visually encoded. Visually encoding for experiment two involved the items being shown as pictures on a projection screen rather than imagining the word in a unique way. For the second the visual/verbal condition, the researcher informed the participants they were going to see a series of pictures and they were to try and remember as many as they could. The second list was to be encoded verbally so the participants were instructed to repeat the words to themselves as many times as they could before the next word was read. After recalling list B, all participants recalled words from list A.

The purpose of experiment two was to keep the visual conditions true to visual encoding. There were no verbal prompts when encoding visually as there were with experiment one (researcher reading the list aloud and having participants visualize the word). The hypothesis remained the same as in experiment one. Encoding lists in different ways will lead to less RI than encoding the two lists in the same manner.

\section{3) Results}

An independent samples $t$ test was computed to assess the differences in retention percentage between the visual/visual encoding condition $(M=64.08, S D=7.99)$ and the visual/verbal encoding condition $(M=84.95, S D=14.91)$. The retention difference was $21 \%$ which was statistically significant, $t(9)=2.98, d=1.82$. Keep in mind that the $n$ for experiment two was small, yet there were some slight differences in terms of recall percentages between the two experiments. For instance, participants in the visual/visual condition (experiment one) recalled about $5 \%$ more words on final recall than participants in the same condition within experiment two. This difference could be an artifact due to 
sample size differences or participant perceptual visual encoding (experiment 1) is different than visual encoding based on actual images.

In order to assess the effect of the condition onpost test retention scores while controlling for the variance associated from pretest scores an analysis of covariance was used. The major assumptions for this analysis were checked and met. Table 6 presents the means and standard deviations for both conditions on post test scores, before and after controlling for pre test scores. Results indicate that after controlling for the pre test scores (list A first recall) there was a significant difference between visual/visual and visual/verbal conditions, $F(1,8)=6.42, p=.035$, partial $^{\text {eta }}{ }^{2}=.45$. Table 7 shows the ANCOVA table which demonstrates that even though there was a significant amount of explained variance associated with the pretest score there was still a statistically significant different between the two conditions on post test score. As was the case with experiment one, encoding lists in different ways produces less RI than encoding two lists in the same way.

\section{Discussion}

The results of the two experiments support the hypotheses that encoding two lists in different ways reduces retroactive interference. It is more important to illustrate how to reduce RI when you consistently participate in memory activities. Encoding two lists in different ways increased retention of list A compared to encoding both lists the same way. Previous research demonstrated that RI can be significantly reduced by cuing the participants about something unique from one of the lists. The two experiments discussed in this paper did not use any type of cuing. Encoding lists in different ways (visual and verbal), rather than cuing, creates less interference upon recall then lists encoded in the same manner.

Statistically the results were consistent across multiple analysis methods (retention score as the dependent variable in ANOVA, ANCOVA, hierarchical regression, and repeated measures ANOVA - not reported in this paper). Controlling for pretest variability appears to be more appropriate than using the retention score. In terms of ease of interpretation and reporting, the ANCOVA is most useful.

Reducing retroactive interference in a classroom may be as simple as differentiating instruction styles. Retention is related to how the information is digested or encoded. The participants in the two experiments were randomly assigned to condition; therefore, ranges in learning styles were most likely equivalent between all groups. If learning styles and other moderating variables were successfully held constant by the research design then the increased retention percentages for certain participants can be explained by the treatment.

Learning styles are less important when instructional approaches and ways of encoding are diverse. Future research should investigate reducing retroactive interference at the classroom level. It is certainly recognized by the research team that it is difficult to assign students to different conditions within schools, however it is be possible to introduce novel ways of teaching to enhance student retention of newly learned content.

\section{References}

Alloway, T. P. (2006). How does working memory work in the classroom? Educational Research and Reviews 1(4), 134-139.

Baddeley, A. D., \& Hitch, G. (1974).Working memory. In G. H. Bower (Ed.), The psychology of learning and motivation: Advances in research and theory. (Vol. 8, pp. 47-89). New York: Academic.

Bower, G. H., \& Mann, T. (1992). Improving recall by recoding interfering material at the time of retrieval. Journal of Experimental Psychology: Learning, Memory, and Cognition, 18(6), 1310-1320. http://dx.doi.org/10.1037/0278-7393.18. 6.1310

Bower, G. H., Thompson-Schill, S., \& Tulving E. (1994). Reducing retroactive interference: an interference analysis. Journal of Experimental Psychology: Learning, Memory, and Cognition, 20(1), 51-66. http://dx.doi.org/10.1037/0278-7393.20.1.51

Bower, G. H., Wagner, A. D., Newman, S. E., Randle, J. D., \& Hodges, M. J. (1996). Does recoding interfering material improve recall? Journal of Experimental Psychology: Learning, Memory, and Cognition, 22(1), 240-245. http://dx.doi.org/10.1037/0278-7393.22.1.240

Brock, S., \&Jogleker, Y. (2011). Empowering PowerPoint: Slides and teaching effectiveness. Interdisciplinary Journal of Information, Knowledge, and Management, 6, 86-93. 
Burns, D. J., \& Gold, D. E. (1999). An analysis of item gains and losses in retroactive interference. Journal of Experimental Psychology: Learning, Memory, and Cognition, 25(4), 978-985. http://dx.doi.org/10.1037/0278-7393.25.4.978

Chandler, C. (1989). Specific retroactive interference in modified recognition tests: evidence for an unknown cause of interference. Journal of Experimental Psychology: Learning, Memory, and Cognition, 15(2), 256-265. http://dx.doi.org/10.1037/0278-7393.15.2.256

Chandler, C. (1993). Accessing related events increases retroactive interference in a matching recognition test. Journal of Experimental Psychology: Learning, Memory, and Cognition, 19(4), 967-974. http://dx.doi.org/10.1037/0278-7393.19.4.967

Coller, B. D., \& Shernoff, D. J. (2009). Video game-based education in mechanical engineering: A look at student engagement. International Journal of Engineering Education 25(2), 308-317.

Cook, T. D., \& Campbell, D. T. (1979). Quasi-experimentation: Design \& analysis issues for field settings. Boston, MA: Houghton Mifflin.

Fitzmaurice, G. M., Laird, N. M., \& Ware, J. h., (2004). Applied longitudinal analysis. Hoboken, NJ: Wiley-Interscience.

Fraser, K. Ma, I., Teteris, E., Lee, M., Wright, B., \& McLaughlin, K. (2012). Learning during simulation training is prone to retroactive interference. Medical Education, 46, 299-305. http://dx.doi.org/10.1111/j.1365-2923.2011.04181.x

Graf, S., Lin, T., \&Kinshuk. (2008). The relationship between learning styles and cognitive traits: Getting additional information for improving student modeling. Computers in Human Behavior, 24(2), 122-137. http://dx.doi.org/10.1016/j.chb.2007.01.004

Gupta, J. K., Srivastava, A. B. L., \& Sharma, K. K. (1988). On the optimum predictive potential of change measures. Journal of Experimental Education, 56, 124-128.

Kamuche, F. U. (2005). Do learning \& teaching styles affect students' performance? An empirical study. Journal of Business \& Economics Research, 3(9), 35-40.

Karpicke, J. D., Butler, A. C., \& Roediger, H. L. (2009). Metacognitive strategies in student learning: Do students practise retrieval when they study on their own? Memory, 17(4), 471-479. http://dx.doi.org/10.1080/09658210802647009

Kazu, I. Y. (2009). The effect of learning styles on education and the teaching process. Journal of Social Sciences, 5(2), 85-94.

Knapp, T. R., \& Schafer, W. D. (2009). From gain score t to ANCOVA F (and vice versa). Practical Assessment, Research \& Evaluation, 14(6), 1-7. [Online] Available: http://pareonline.net/getvn.asp? $\mathrm{v}=14 \& \mathrm{n}=6$

Marsh, R. L., Landau, J. D., \& Hicks J. L. (1996). The postinformation effect and reductions in retroactive interference. Journal of Experimental Psychology: Learning, Memory, and Cognition, 22(5), 1296-1303. http://dx.doi.org/10.1037/0278-7393.22.5.1296

Michel, N., Cater, J. J., \& Varela, O. (2009). Active versus passive teaching styles: An empirical study of student learning outcomes. Human Resource Development Quarterly, 20(4), 397-418. http://dx.doi.org/10.1002hrdq.20025

Morgan, G. A., Gliner, J. A., \& Harmon, R. J. (2006). Understanding and evaluating research in applied and clinical settings. Mahwah, NJ: Lawrence Erlbaum.

Rassaian, N. (2001). Long-term memory and learning through the use of research centered teaching method. Journal of Medical Education 1(1), 38-42. 
Table 1. Means, Standard Deviations, and Analysis of Variance for Retention as a Function of Experimental Condition

\begin{tabular}{|c|c|c|c|c|}
\hline \multirow[b]{2}{*}{ Condition } & \multicolumn{2}{|c|}{ Retention } & \multirow[b]{2}{*}{$F$} & \multirow[b]{2}{*}{$p$} \\
\hline & $M$ & $S D$ & & \\
\hline & & & 10.43 & $<.001$ \\
\hline Verbal/Verbal & 58.86 & 18.61 & & \\
\hline Visual/Visual & 69.03 & 18.49 & & \\
\hline Verbal/Visual & 73.87 & 18.34 & & \\
\hline Visual/Verbal & 84.03 & 16.94 & & \\
\hline Verbal/- & 91.17 & 8.37 & & \\
\hline Visual/- & 93.77 & 8.85 & & \\
\hline
\end{tabular}

Table 2. Means, Standard Deviations, and Analysis of Variance for Retention as a Function of Encoding Series

\begin{tabular}{lllll}
\hline \multirow{2}{*}{ Condition } & \multicolumn{2}{l}{ Retention } & & \\
\cline { 2 - 5 } Same Encoding & $M$ & $S D$ & $F$ & \\
\hline Different Encoding & 63.94 & 18.98 & & \\
No Interference & 79.68 & 18.02 & & \\
& 92.57 & 8.55 & & \\
\hline
\end{tabular}

Table 3. Adjusted and Unadjusted Condition Means and Variability for Posttest Scores Using Pretest Scores as a Covariate

\begin{tabular}{|c|c|c|c|c|c|}
\hline & & & Unadjusted & & Adjusted \\
\hline Condition & $N$ & $M$ & $S D$ & $M$ & $S E$ \\
\hline Same Encoding & 34 & 7.41 & 3.13 & 7.67 & .27 \\
\hline Different Encoding & 35 & 9.09 & 3.05 & 9.17 & .27 \\
\hline No Interference & 24 & 11.04 & 2.63 & 10.55 & .33 \\
\hline
\end{tabular}


Table 4. Analysis of Covariance for Posttest Scores as a Function of Condition, Using Pretest Scores as a Covariate

\begin{tabular}{llllll}
\hline Source & $d f$ & $M S$ & $F$ & $p$ & partial eta $^{2}$ \\
\hline Pretest & 1 & 574.21 & 228.43 & $<.001$ & .72 \\
Condition & 2 & 58.75 & 23.37 & $<.001$ & .34 \\
Error & 89 & 2.51 & & & \\
\hline
\end{tabular}

Table 5. Hierarchical Multiple Regression Analysis Summary for Condition and Interaction of Condition by Pretest Scores, while Controlling for Pretest Scores

\begin{tabular}{|c|c|c|c|c|c|c|}
\hline & Variable & $B$ & $S E B$ & $\beta$ & $R^{2}$ & $\Delta R^{2}$ \\
\hline \multirow[t]{3}{*}{ Step 1} & & & & & .65 & .65 \\
\hline & Pretest & 1.08 & .08 & $.81 * * *$ & & \\
\hline & Constant & -3.32 & .96 & & & \\
\hline \multirow[t]{5}{*}{ Step 2} & & & & & .77 & .12 \\
\hline & Pretest & 1.03 & .07 & $.77 * * *$ & & \\
\hline & Condition & -1.46 & .23 & $-.35 * * *$ & & \\
\hline & Condition & .04 & .23 & .01 & & \\
\hline & Constant & -2.58 & .78 & & & \\
\hline \multirow[t]{7}{*}{ Step 3} & & & & & .78 & .003 \\
\hline & Pretest & 1.03 & .07 & $.77 * * *$ & & \\
\hline & Condition & -2.56 & 1.12 & $-.62 *$ & & \\
\hline & Condition & .78 & 1.09 & .19 & & \\
\hline & Interaction & .10 & .10 & .28 & & \\
\hline & Interaction & -.07 & .09 & -.19 & & \\
\hline & Constant & -2.57 & .82 & & & \\
\hline
\end{tabular}

${ }^{*} p<.05 ; * * p<.01, * * * \overline{p<.001}$

Table 6.Adjusted and Unadjusted Condition Means and Variability for Posttest Scores Using Pretest Scores as a Covariate (Experiment Two)

\begin{tabular}{|c|c|c|c|c|c|}
\hline \multirow[b]{2}{*}{ Condition } & \multirow[b]{2}{*}{$N$} & \multirow[b]{2}{*}{$M$} & \multirow{2}{*}{$\begin{array}{c}\text { Unadjusted } \\
S D\end{array}$} & \multirow[b]{2}{*}{$M$} & djusted \\
\hline & & & & & $S E$ \\
\hline Visual/Visual & 6 & 7.67 & 1.37 & 7.92 & .68 \\
\hline Visual/Verbal & 5 & 10.80 & 3.35 & 10.50 & .75 \\
\hline
\end{tabular}


Table 7. Analysis of Covariance for Posttest Scores as a Function of Condition, Using Pretest Scores as a Covariate (Experiment Two)

\begin{tabular}{llllll}
\hline Source & $d f$ & $M S$ & $F$ & $p$ & partial eta $^{2}$ \\
\hline Pretest & 1 & 32.18 & 11.73 & .009 & .59 \\
Condition & 1 & 17.62 & 6.42 & .035 & .45 \\
Error & 8 & 2.74 & & & \\
\hline
\end{tabular}

\section{Appendix A}

List A

truck, spinach, giraffe, bookcase, onion, motorcycle, cabinet, zebra, subway, lamp, celery, cow, desk, boat, squirrel, cabbage

\section{List B}

Violin, cucumber, elephant, closet, turnip, guitar, basement, sheep, clarinet, garage, corn, rabbit, patio, saxophone, tiger, radishes

Appendix B

Experiment One

\begin{tabular}{|l|l|l|l|l|l|l|}
\hline Condition & LIST A & $\begin{array}{l}\text { Recall } \\
\mathrm{A}\end{array}$ & LIST B & $\begin{array}{l}\text { Recall } \\
\mathrm{B}\end{array}$ & $\begin{array}{l}\text { Recall } \\
\mathrm{A}\end{array}$ \\
\hline 1 & VERBAL & $\mathrm{X}$ & VERBAL & $\mathrm{X}$ & $\mathrm{X}$ \\
\hline 2 & *VISUAL & $\mathrm{X}$ & *VISUAL & $\mathrm{X}$ & $\mathrm{X}$ \\
\hline 3 & VERBAL & $\mathrm{X}$ & *VISUAL & $\mathrm{X}$ & $\mathrm{X}$ \\
\hline 4 & *VISUAL & $\mathrm{X}$ & VERBAL & $\mathrm{X}$ & $\mathrm{X}$ \\
\hline 5 & & & & & \\
\hline 6 & VERBAL & $\mathrm{X}$ & Time filler no list & $\mathrm{NA}$ & $\mathrm{X}$ \\
\hline & & & & $\mathrm{X}$ & \\
\hline
\end{tabular}

* Visual encoding was obtained by having the participants visualize the words that were read by the researcher

Experiment Two

\begin{tabular}{|c|c|c|c|c|c|c|}
\hline 1 & $* *$ VISUAL & $\mathrm{X}$ & $* *$ VISUAL & $\mathrm{X}$ & $\mathrm{X}$ \\
\hline 2 & $* *$ VISUAL & $\mathrm{X}$ & VERBAL & $\mathrm{X}$ & $\mathrm{X}$ \\
\hline
\end{tabular}

** Visual encoding was obtained by showing the participants pictures of the words 